\title{
Blood Ammonia Measurement Using a Simple Reflectometer
}

\author{
By R. N. Ratnaike
}

The Department of Medicine, The University of Adelaide, The Queen Elizabeth Hospital, Woodville, South Australia 5011

\section{J. E. Buttery}

Department of Clinical Chemistry, The Queen Elizabeth Hospital, Woodville, South Australia 5011 and

\section{Sheryl Hoffmann}

The Department of Medicine, The University of Adelaide, The Queen Elizabeth Hospital, Woodville, South Australia 5011

(Received June 27/October 19, 1983)

Summary: We have assessed a compact Blood Ammonia Checker System (Ammonia Checker) consisting of a reflectometer which measures the intensity of colour formed by blood ammonia on a bromocresol green indicator reagent plate. The results show good correlation $(r=0.95)$ with our routine chemical method and a regression line $y=0.835 x-1.468$. The Ammonia Checker has good precision $(C V<10 \%)$ at the critical blood ammonia concentration and accurately measures predetermined ammonia concentrations. Blood sampling is improved with a precision pipette. The Ammonia Checker is simple, convenient and reliable and is ideally suited for a laboratory required to perform an urgent blood ammonia measurement.

\section{Bestimmung von Ammoniak im Blut mit einem einfachen Reflektometer}

Zusammenfassung: Wir prüften ein kompaktes System zur Bestimmung von Ammoniak im Blut (Ammonia Checker), bestehend aus einem Reflektometer, das die Intensität der von Ammoniak im Blut auf einer Bromkresolgrün-Indikator-Reagenz-Platte verursachten Farbe mißt. Die Ergebnisse zeigen eine gute Korrelation $(r=0,95)$ mit unserer chemischen Routinemethode und eine Regressionsgerade von $y=0,835 x-$ 1,468. Der Ammonia Checker zeigt eine gute Präzision (VK $<10 \%$ ) bei der kritischen Konzentration von Ammoniak im Blut und mißt vorher bestimmte Ammoniakkonzentrationen genau. Die Gewinnung der Blutproben wurde durch Verwendung einer Präzisionspipette verbessert. Der Ammonia Checker ist einfach, bequem und zuverlässig und ist ideal geeignet für Laboratorien, von denen die Durchführung eiliger Ammoniak-B̈estimmung im Blut erwartet wird.

\section{Introduction}

The measurement of ammonia is a useful index in the assessment of portal-systemic encephalopathy (1) and in the diagnosis of hyperammonaemic states such as urea cycle disorders (2). More recently, hyperammonaemia has been reported with the use of valproate in epilepsy (3). Thus a rapid and reliable test to screen patients for hyperammonaemia would be of value.
The more widely used methods for ammonia measurement are time consuming and involve ion-exchange (4), enzymatic reactions (5) or microdiffusion (6), requiring technical expertise and laboratory facilities. A Blood Ammonia Checker System (Ammonia Checker) is available for the rapid and convenient determination of blood ammonia. In this paper, we report our assessment of the Ammonia Checker. 


\section{Materials and Methods}

The Ammonia Checker (fig. 1) manufactured by Kyotot Daiichi Kagaku Co. Ltd., 57 Nishi Aketa-cho, Higashi Kujo Minami-Ku, Kyoto 601 , Japan is a compact machine $(100 \mathrm{~mm} \times 175 \mathrm{~mm} \times 50$ $\mathrm{mm}$ ) consisting of a reflectometer which measures the colour formed by ammonia on a reagent plate. Ammonia is liberated when the blood specimen comes in contact with the alkaline buffer reagent in the test hole (fig. 2). The liberated ammonia gas diffuses through a polypropylene film to the indicator to form a blue colour, the intensity of which is proportional to the ammonia concentration. This method is based on the principle of microdiffusion of ammonia in blood.

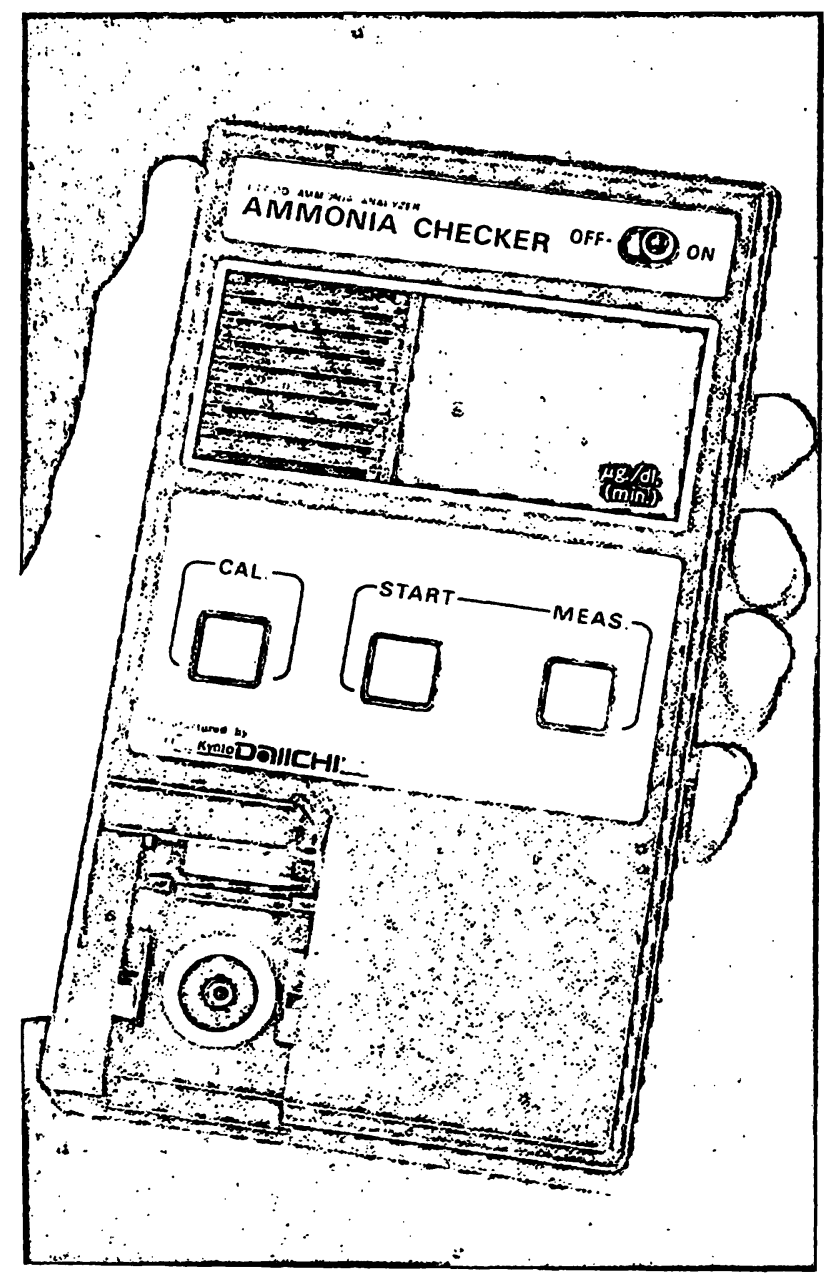

Fig. 1. Blood Ammonia Checker System.

Blood $(20 \mu \mathrm{l})$ is applied to the test hole of the reagent plate, sealed and shaken 10 times and left to stand at room temperature for $15 \mathrm{~min}$. The plate is then inserted into the optical chamber of the reflectometer which displays the ammonia concentration.

For blood collection, the skin surface is cleaned with a cotton swab to remove traces of dermal ammonia. The blood is collected in a heparinised tube and sent immediately to the laboratory and tested employing the precautions necessary to prevent the false elevation of ammonia concentration (7). Anti-coagulants such as potassium oxalate and ammonium oxalate are unsuitable. Specimens haemolysed or with high bilirubin concentration have no adverse effect on the determination.

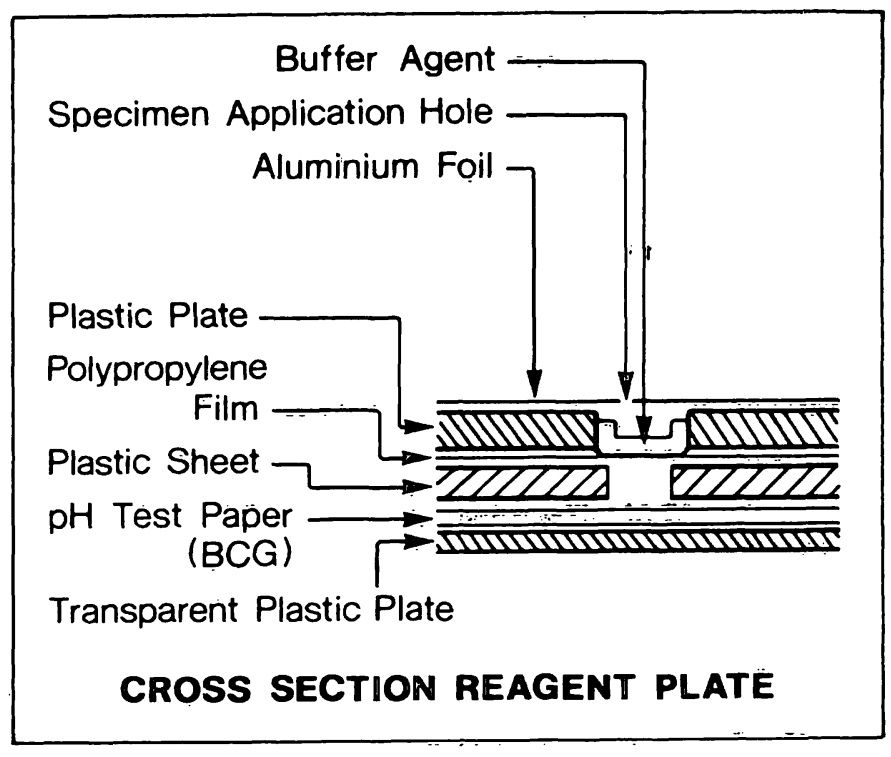

Fig. 2. Schematic cross section diagram of the Reagent Plate.

Blood specimens were collected from normal subjects, patients with liver disease and those on sodium valproate and assayed in duplicate by the Ammonia Checker and, for comparison, by our modified Hyland method (8). This assay involves the selective adsorption of ammonia from blood onto an acidic cation exchange resin. The ammonia is eluted with $4.0 \mathrm{~mol} / 1 \mathrm{NaCl}$ and quantitated using the Berthelot reaction. To extend the range of ammonia concentrations stored blood and blood with added ammonia were also assayed.

\section{Results and Discussion}

\section{Comparison between the two methods}

Blood ammonia results $(n=30)$ from normal subjects and from patients with liver disease obtained by the Ammonia Checker and the chemical method showed good correlation, $\mathrm{r}=0.95(\mathrm{t}=16.8, \mathrm{p}$ $<0.001$ ), with a linear regression line, $y=0.835 x-$ 1.468 (fig. 3), as by Deming's.procedure. The mean blood ammonia values of the above groups by the Ammonia Checker and the chemical method are 72 $\mu \mathrm{mol} / \mathrm{l}$ and $88 \mu \mathrm{mol} / 1$ respectively.

In eighteen patients on valproate, five patients had elevated blood ammonia (upper limits of reference range is $37 \mu \mathrm{mol} / \mathrm{l}$ ) by the chemical method (mean $76.1 \mu \mathrm{mol} / \mathrm{l}$ ) and by the Ammonia Checker (mean $64.3 \mu \mathrm{mol} / \mathrm{l})$. The results are generally lower by the Ammonia Checker but on comparing the results of the two methods there was no significant difference (paired t-test, $\mathrm{t}=0.61, \mathrm{p} .>0.1$ ). ' 


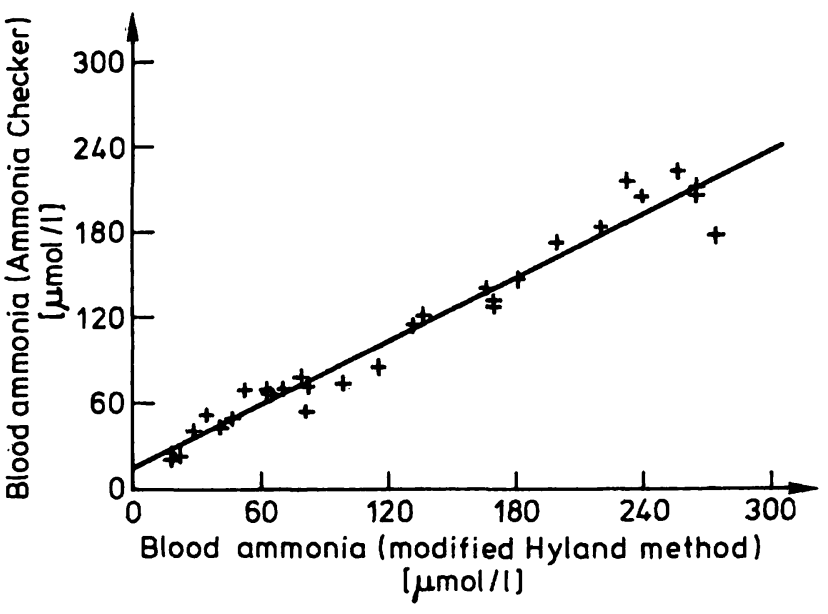

Fig. 3. Correlation of blood ammonia determined by the Ammonia Checker and the modified Hyland method.

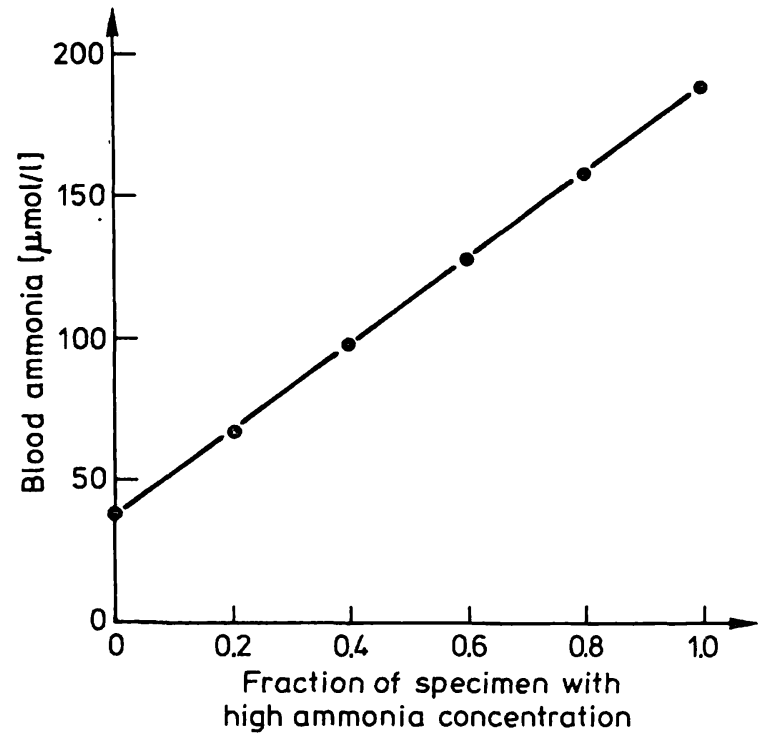

Fig. 4. Blood ammonia concentrations determined from two specimens with low and high ammonia concentrations.

Tab. 1. Recovery of ammonia added to fresh heparinised blood.

\begin{tabular}{lll}
\hline $\begin{array}{l}\text { Ammonia added } \\
(\mu \mathrm{mol} / \mathrm{I})\end{array}$ & $\begin{array}{l}\text { Ammonia recovered } \\
(\mu \mathrm{mol} / \mathrm{I})^{*}\end{array}$ & $\begin{array}{l}\text { Recovery, } \\
\text { fraction }\end{array}$ \\
\hline 40 & 31 & 0.78 \\
80 & 63 & 0.79 \\
120 & 90 & 0.75 \\
160 & 121 & 0.76 \\
200 & 152 & 0.76 \\
\hline
\end{tabular}

* Mean of duplicate assay

To further assess accuracy of the Ammonia Checker, from two specimens with low and high ammonia concentrations, four blood samples were prepared in the following proportions: 4 low/ 1 high, 3 low/ 2 high, 2 low $/ 3$ high, 1 low $/ 4$ high.

The results of the ammonia concentrations of the low, high and the four mixed samples fell along a straight line (fig. 4) and were within the measuring limit of the Ammonia Checker (235 $\mu \mathrm{mol} / \mathrm{l})$; thus showing the ability of the Ammonia Checker to measure ammonia concentrations accurately.

\section{Recovery}

Known concentrations of ammonia (as ammonium sulphate) in physiological saline were added to fresh blood: The recoveries obtained ranged from 75$79 \%$ (tab. 1). The poor recovery confirms the findings of Hutchinson \& Labby (10), and is due to the instability of ammonia when added to fresh blood and not the inaccuracy of the method.

\section{Precision}

The within-run precision of blood specimens with normal, slightly abnormal and abnormal ammonia concentrations is shown in table 2 . The precision at the different concentrations of ammonia was good. Between-run precision for blood ammonia cannot be determined owing to specimen instability.

Tab. 2. Within-run precision of blood ammonia for the Ammonia Checker $(n=12)$.

\begin{tabular}{lccc}
\hline & \multicolumn{3}{l}{ Blood ammonia } \\
& Normal & $\begin{array}{l}\text { Slightly } \\
\text { abnormal }\end{array}$ & Abnormal \\
\hline Mean $(\mu \mathrm{mol} / \mathrm{l})$ & 18 & 52 & 176 \\
$\operatorname{SD}(\mu \mathrm{mol} / \mathrm{l})$ & 1.6 & 3.5 & 11.5 \\
$\mathrm{CV}(\%)$ & 8.9 & 6.7 & 6.5 \\
\hline
\end{tabular}




\section{Timing error}

The consequence of a timing error of $1 / 2$ and $1 \mathrm{~min}$ beyond the specified $15 \mathrm{~min}$ reaction period caused a minimal elevation of blood ammonia (tab. 3).

Tab. 3. Changes in blood ammonia concentration due to timing error.

\begin{tabular}{lcccr}
\hline $\begin{array}{l}\text { Blood ammonia } \\
(\mu \mathrm{mol} / \mathrm{l})\end{array}$ & $\begin{array}{l}\text { No. of } \\
\text { assays }\end{array}$ & \multicolumn{2}{l}{$\begin{array}{l}\text { Mean blood ammonia } \\
(\mu \mathrm{mol} / \mathrm{l})\end{array}$} & \\
& & $15 \mathrm{~min}$ & $+1 / 2 \mathrm{~min}$ & $+1 \mathrm{~min}$ \\
\hline$<50$ & 7 & 25.5 & 25.8 & 26.8 \\
$50-100$ & 11 & 65.0 & 66.0 & 67.2 \\
$101-220$ & 12 & 170.0 & 172.6 & 175.7 \\
\hline
\end{tabular}

\section{Quality control}

There is no commercially available quality control material for blood ammonia. It is not possible to use a frozen blood specimen as QC material owing to its instability during the thawing stage. We have used an aqueous ammonia solution $(150 \mu \mathrm{mol} / \mathrm{l})$ for quality control and although the results were consistently higher by 5 to 10 per cent, this solution will assess the overall performance of the Ammonia Checker.

\section{Blood sampling in the assay}

As our interest in the Ammonia Checker was for laboratory use, we investigated blood sampling using a precision pipette (Finn pipette, Labsystem Oy, 00210 Helsinki 21, Finland) and the capillary supplied by the manufacturer. Our data (tab. 4) shows that the precision was better using the pipette than the capillary.

Tab. 4. Precision studies on blood sampling using a Finn pipette and a capillary.

\begin{tabular}{lll}
\hline & Weight of $20 \mu$ blood & \\
& Finn pipette & Capillary \\
\hline Range (mg) & $19.1-21.7$ & $18.4-22.4$ \\
Mean (mg) & 20.4 & 20.4 \\
SD (mg) & 0.75 & 1.5 \\
CV (\%) & 3.7 & 7.3 \\
\hline
\end{tabular}

We have shown the Ammonia Checker as a reliable means of measuring blood ammonia in the routine laboratory and the results compared very favourably with those obtained by our chemical method. In addition the Ammonia Checker is easy to operate, economical and provides an urgent result on a single blood specimen in 15 minutes.

\section{References}

1. Phillips, G. B., Schwartz, R., Gabuzda, G. J. \& Davidson, C. S. (1952) N. Eng. J. Med. 247, 239-246.

2. Hsia, E. Y. (1974) Gastroenterology 67, 347-374.

3. Coulter, D. L. \& Allan, R. J. (1980) Lancet 1, 1310-1311.

4. Forman, D. T. (1964) Clin. Chem. 10, 497-508.

5. Mondzac, A., Ehrlich, G. E. \& Seegmiller, J. E. (1965) J. Lab. Clin. Med. 66, 526-531.

6. Rosenoer, V. M. (1959) J. Clin. Pathol. 12, 128-130.

7. Gerron, G. G., Ansley, J. D., Isaacs, J. W., Kutner, M. H. \& Rudman, D. (1976) Clin. Chem. 22, 663-666.

8. Buttery, J. E., Ratnaike, R. N. \& Chamberlain, B. R. (1982) J. Clin. Chem. Clin. Biochem. 20, 447-450.

9. Evaluation Data on Blood Ammonia Checker System. Kyoto Daiichi Kagaku Co. Ltd. Japan.

10. Hutchinson, J. H. \& Labby, D. H. (1962) J. Lab. Clin. Med. $60,170-178$.

Dr. R. N. Ratnaike,

The Department of Medicine,

The University of Adelaide,

The Queen Elizabeth .Hospital,

Woodville, S.A. 5011

Australia 